ВІСНИК

ОДЕСЬКОГО НАЦІОНАЛЬНОГО

МОРСЬКОГО УНІВЕРСИТЕТУ
HERALD

OF THE ODESSA NATIONAL

MARITIME UNIVERSITY № 1 (64), 2021

1УДК 641. 546.45

DOI 10.47049/2226-1893-2021-1-60-71

\title{
УСОВЕРШЕНСТВОВАНИЕ ТЕРМОДИНАМИЧЕСКОГО ЦИКЛА ХОЛОДИЛЬНОЙ УСТАНОВКИ РЕФРИЖЕРАТОРНОГО КОНТЕЙНЕРА ДЛЯ ПЕРЕВОЗКИ И ХРАНЕНИЯ ВАКЦИНЫ NVX-CoV2373
}

\section{А.А. Вассерман}

доктор технических наук, профессор кафедры «Судовые энергетические установки и техническая эксплуатация»

\section{А.Г. Слынько}

кандидат технических наук, профессор кафедры «Судовые энергетические установки и техническая эксплуатация»

Одесский национальный морской университет, Украина, Одесса

Аннотация. Предлагается оборудовать рефрижераторные контейнеры для перевозки и хранения вакцины NVX-CoV2373 модифицированными холодильными установками. Модификации подвержен термодинамический иикл холодильной установки. Суть модификации состоит в замене адиабатных процессов сжатия рабочих тел во всех циклах двухкаскадной холодильной установки политропными прочессами.

Расчёты показали, что при таком усовершенствовании термодинамического ичила холодильной установки суточная экономия электроэнергии составит на один контейнер около $100 \mathrm{\kappa Bm} \cdot ч а с$, а годовая - более $35 \mathrm{MBm}$ час, что соответствует больше 26 кг/сут. или около $10 \mathrm{~m} / 2 о д$ дизельного топлива при использовании для получения электроэнергии дизель генератора с удельным расходом топлива $0,270 \mathrm{\kappa} / \mathrm{\kappa Bm} \cdot ч а \mathrm{c}$.

Ключевые слова: рефрижераторный контейнер, холодильная установка, усовершенствование термодинамического иикла, адиабатныий и политропный проиесс, эффективность работьл.

УДК 641. 546.45

DOI 10.47049/2226-1893-2021-1-60-71

\section{УДОСКОНАЛЕННЯ ТЕРМОДИНАМІЧНОГО ЦИКЛУ ХОЛОДИЛЬНОӤ УСТАНОВКИ РЕФРИЖЕРАТОРНОГО КОНТЕЙНЕРА ДЛЯ ТРАНСПОРТУВАННЯ ТА ЗБЕРІГАННЯ ВАКЦИНИ NVX-CoV2373}

\section{О.А. Вассерман}

доктор технічних наук, професор кафедри

«Суднові енергетичні установки та технічна експлуатація»

$$
\text { О.Г. Слинько }
$$

кандидат технічних наук, професор кафедри

«Суднові енергетичні установки та·технічна експлуатація»

Одеський національний морський університет, Україна, Одеса

(C) Вассерман О.А., Слинько О.Г., 2021 
Анотація. Пропонується рефрижераторні контейнери для транспортування i зберігання вакцини NVX-CoV2373 обладнувати холодильними установками з модифікованими термодинамічними циклами. Сенс модифікачії заключається в заміні адіабатних процесів стиснення робочих тіл в двокаскадній холодильній установиі політропними процесами. Розрахунки показали, щцо при такому удосконаленню термодинамічного ичиклу холодильної установки добова економія електроенергії на один контейнер складе майже 100 кВтггод, а річна - більш ніж 35 МВтггод, ще відповідає економії більш ніж 26 кг/добу, або $10 \mathrm{~m} / \mathrm{pi \kappa}$ дизельного палива при використанні для вироблення електричної енергії дизель генератора, питома витрата палива в якому дорівнює $0,270 \kappa 2 / \kappa B m . г о д$

Ключові слова: рефрижераторний контейнер, холодильна установка, удосконалення термодинамічного ииклу, адіабатний і політропний проиес стиснення, ефективність роботи.

UDC 641. 546.45

DOI 10.47049/2226-1893-2021-1-60-71

\title{
IMPROVEMENT OF THERMODYNAMIC CYCLE REFRIGERATING INSTALLATION CONTAINER FOR TRANSPORTATION AND STORAGE OF VACCINE NVX-Cov2373
}

\author{
A.A. Vasserman \\ Doctor of technical sciences, \\ Professor of department «Ships energetic plants and technical operation» \\ A.G. Slyn 'ko \\ Candidate of technical sciences, \\ Professor of department «Ships energetic plants and technical operation»

\section{Odessa National Maritime University, Ukraine, Odessa}

\begin{abstract}
The issue of equipping refrigerated containers for transportation and storage of the NVX-CoV2373 vaccine with modified refrigeration units is being considered. The thermodynamic cycle of the refrigeration unit is subject to modification. The essence of the modification consists in replacing adiabat processes of compression of working bodies in all cycles of a two-stage refrigeration unit with polytropic processes. It is proposed to re-equip the standard 20-foot containers that are widely used today, since the infrastructure for their transportation and storage by sea, rail and air transport is already ready. Calculations have shown that with such an improvement in the thermodynamic cycle of the refrigeration unit, the daily energy savings will be about $100 \mathrm{kWh}$ per container, and the annual energy savings will be more than $35 \mathrm{MWh}$, which corresponds to savings of more than $26 \mathrm{~kg} /$ day or about
\end{abstract}


10 tons / year of fuel, when using a diesel generator for generating electricity with a specific fuel consumption of $0.270 \mathrm{~kg} / \mathrm{kWh}$.

Keywords: refrigerated container, refrigeration unit, improvement of the thermodynamic cycle, adiabatic and political process, efficiency.

Введение. В настоящее время в мире актуальна проблема перевозки и хранения вакцины $N V X-C o V 2373$, что обусловлено низкой температурой её сохранения и использования. В соответствии с технологией её получения и использования эта температура равна минус $77^{\circ} \mathrm{C}$. Создать и поддерживать такую температуру даже в ограниченном пространстве можно только при помощи двухкаскадной холодильной установки. При этом желательно с точки зрения надёжной работы этой установки, чтобы рабочие вещества обеих ветвей каскада работали при возможно низких давлениях. В соответствии нашими предыдущими исследованиями [8] в качестве таких хладагентов могут использоваться в нижней ветви каскада этан, а в верхней - пропилен. Выбор этих хладагентов объясняется тем, что температура нормального кипения этана равна минус $88^{\circ} \mathrm{C}$, а пропилен проявил себя как эффективный заменитель широко использовавшегося фреона R22 [8]. Выбор 20-футового контейнера в качестве объекта для перевозки и хранения вакцины $N V X-C o V 2373$ обусловлен наличием инфраструктуры для морской, железнодорожной и авиационной перевозки контейнеров различных типоразмеров.

Теплопритоки в 20-футовый контейнер, при принятом коэффициенте теплопередачи $0,5 \mathrm{BT} /\left(\mathrm{M}^{2} . К\right)$, температуре внутри контейнера минус $77{ }^{\circ} \mathrm{C}$ и температуре окружающей среды $45^{\circ} \mathrm{C}$ равны 4,1 кВт. Для 40 футового контейнера теплопритоки при этих же условиях в два раза больше $(8,99$ кВт).

Целью статьи является рассмотрение способа уменьшения потребляемой холодильной установкой рефрижераторного контейнера электроэнергии для создания и поддержания внутри него указанной температуры. В работах $[1 ; 2]$ показано, что наиболее эффективным термодинамическим циклом холодильной машины является цикл с изотермическим процессом сжатия хладагента. Осуществить строго изотермический процесс сжатия практически невозможно, а политропный процесс сжатия вполне осуществим. Причём политропный процесс сжатия приближается к изотермическому процессу с увеличением интенсивности охлаждения компрессора, сжимающего рабочее тело. Поэтому, в соответствии с предлагаемым способом, все адиабатные процессы сжатия рабочих тел в термодинамическом цикле двухкаскадной холодильной установки рефрижераторного контейнера заменяются политропными. Необходимые при этом соответствующие процессы охлаждения компрессоров, осуществляются её же рабочими веществами при условии, что в конечном итоге теплота отводится в конденсаторе в окружающую среду. В работах [3-8] приво- 
дятся примеры успешного практического применения этого подхода в решении важных задач, связанных с криогенными установками.

Изложение основного материала. Сначала рассмотрим принцип действия простой базовой двухкаскадной холодильной установки. На рис. 1 изображен на диаграмме T,s её термодинамический цикл без регенеративного теплообмена в нижних ступенях и полным промежуточным охлаждением хладагентов в верхней ступени обеих ветвей каскада. Это упрощает расчёты и несущественно влияет на решение поставленной задачи. Жирными линиями изображён двухступенчатый цикл нижней ветви каскада, рабочим телом которой является этан. Соответственно жирными арабскими цифрами обозначены его характерные точки. Цикл верхней ветви каскада (также двухступенчатый) изображён тонкими линиями, а его характерные точки обозначены тонкими цифрами со штрихами. Рабочим телом верхней ветви каскада является пропилен. Линиями 1-2 и 3-4, а также 1'-2' и 3'-4' изображены адиабатные процессы сжатия в нижней и верхней ветвях каскада соответственно.

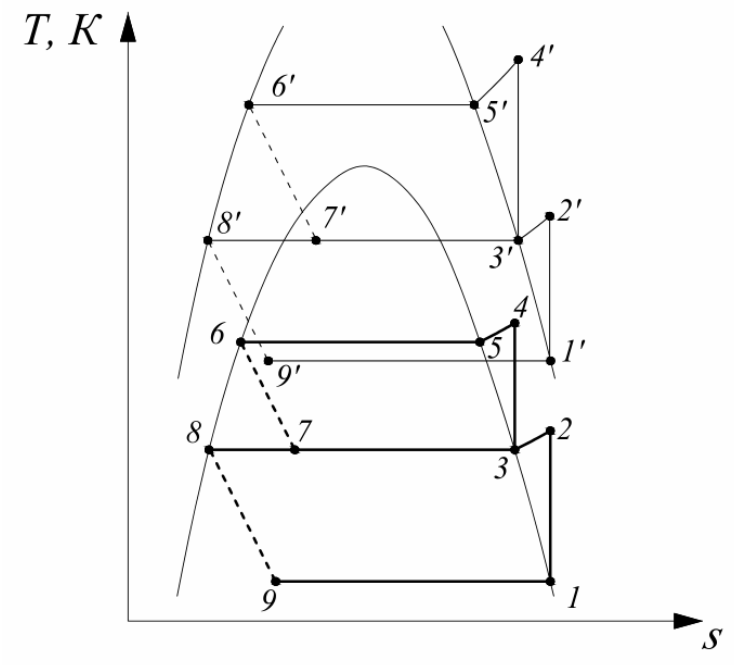

Рис. 1. Термодинамический ичкл простой двухкаскадной холодильной установки с адиабатными процессами сжатия рабочих тел

На рис. 2 изображена принципиальная схема базовой двухкаскадной холодильной установки. Римскими цифрами обозначены её элементы, названия которых приводятся в подрисуночной подписи. Из совместного рассмотрения рис. 1 и рис. 2 легко уяснить известный принцип действия такой двухкаскадной холодильной установки. 
ВІСНИК

ОДЕСЬКОГО НАЦІОНАЛЬНОГО

МОРСЬКОГО УНІВЕРСИТЕТУ

№ 1 (64), 2021
HERALD

OF THE ODESSA NATIONAL

MARITIME UNIVERSITY № 1 (64), 2021

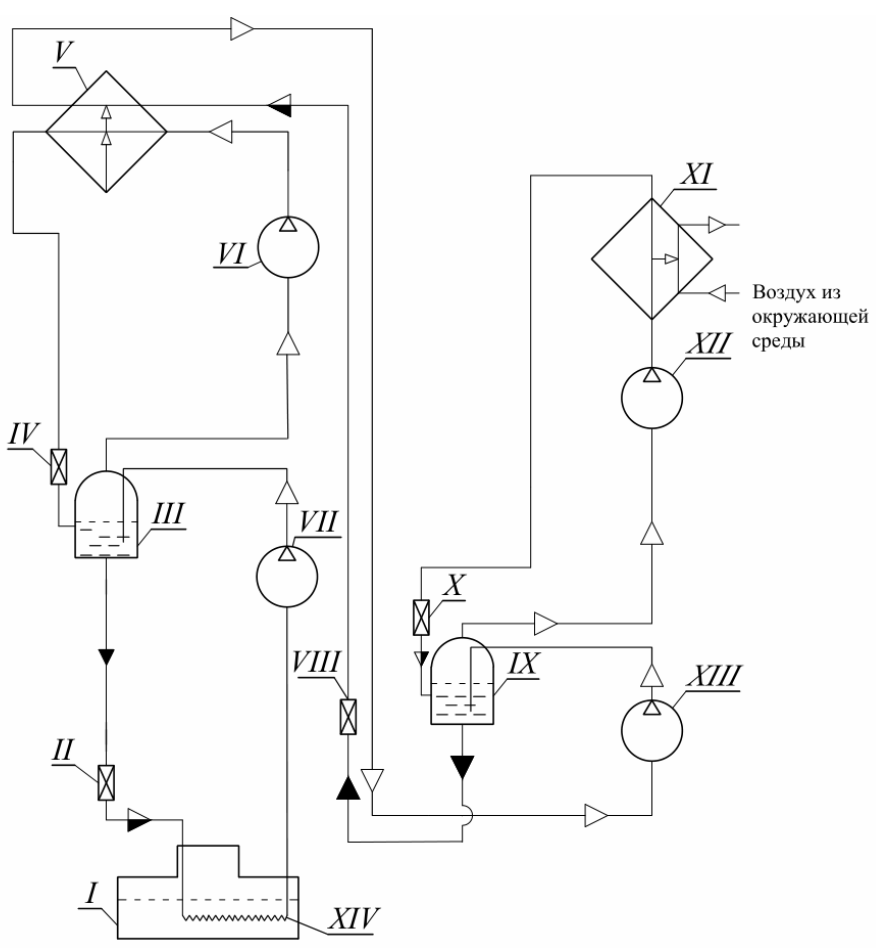

Рис. 2. Принциипиальная схема двухкаскадной холодильной установки с адиабатными прочессами сжатия рабочих тел:

$\boldsymbol{I}$ - рефрижераторный контейнер; II - дроссельный вентиль, через который хладагент подаётся в контейнер; III- промсосуд нижней ветви каскада; IV - дроссель между второй и первой ступенью сжатия нижней ветви каскада; $\boldsymbol{V}$ - конденсатор-испаритель

(этан конденсируется, пропилен кипит); VI- КВД нижней ветви каскада; VII - КНД нижней ветви каскада; VII - дроссельный вентиль, через который жидкий пропилен поступает в конденсатор-испаритель;

$\boldsymbol{I X}$ - промсосуд верхней ветви каскада; $\boldsymbol{X}$-дроссель между второй и первой ступенью сжатия верхней ветви каскада; XI- конденсатор установки; XII-КВД верхней ветви каскада; XIII-КНД верхней ветви каскада; XIV - испаритель установки

На рис. 3 на диаграмме T,s изображён термодинамический цикл модифицированной двухкаскадной холодильной установки с предельным регенеративным теплообменом между паром и жидкостью и политропными процессами сжатия пара хладагентов во всех ступенях и ветвях каскада. В процессах 10-11, 13-1 и 7-8, 2-4 нижней ветви каскада, а также в процессах $10^{\prime}-11^{\prime}, 13^{\prime}-1^{\prime}$, и $7^{\prime}-8^{\prime}, 2^{\prime}-4^{\prime}$ верхней ветви каскада осуществляется предельный регенеративный теплообмен: жидкость охлаждается, а пар перегревается до соответствующей ему предельной температуры. 
ВІСНИК

ОДЕСЬКОГО НАЦІОНАЛЬНОГО

МОРСЬКОГО УНІВЕРСИТЕТУ
HERALD

OF THE ODESSA NATIONAL

MARITIME UNIVERSITY № 1 (64), 2021

В процессах 1-3 и 4-6 нижней ветви каскада и 1'-3' и 4'-6' верхней ветви осуществляется политропное сжатие рабочих тел путём соответствующего охлаждения компрессоров. Значение температуры пара хладагента в конце его политропного сжатия принималось на $10{ }^{\circ} \mathrm{C}$ выше температуры начала сжатия.

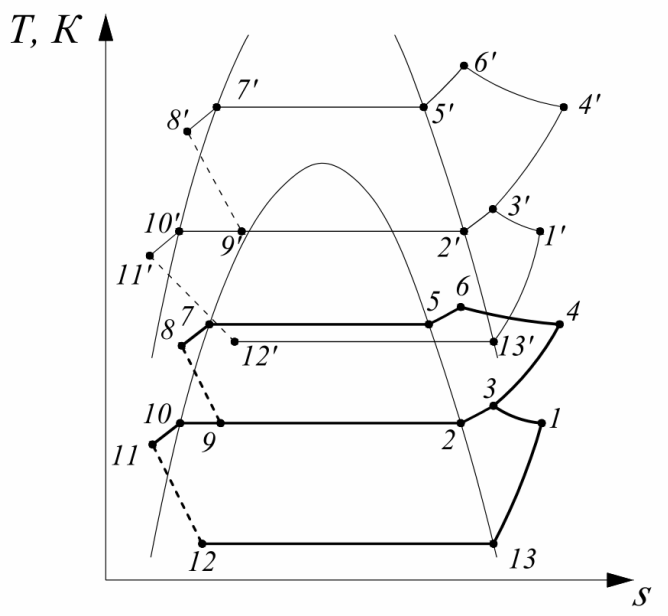

Рис. 3. Термодинамический ичкл двухкаскадной холодильной установки с политропными процессами сжатия рабочих тел

Компрессор низкого давления (КНД) нижней ветви каскада охлаждается жидким этаном, отбираемым из испарителя установки. Компрессор высокого давления (КВД) этой ветви каскада и КНД верхней ветви каскада охлаждаются жидким пропиленом, отбираемым из конденсатора-испарителя. Компрессор высокого давления верхней ветви каскада, как и конденсатор установки, охлаждается воздухом из окружающей среды. Всё это увеличивает расходы хладагентов, циркулирующих в обеих ветвях каскада, но несущественно сказывается на соответствующих работах сжатия.

На рис. 4 изображена принципиальная схема модифицированной двухкаскадной холодильной установки с политропными процессами сжатия рабочих тел во всех ступенях и ветвях каскада. Отличительной особенностью её является изображение компрессоров концентричными окружностями, подчеркивающими наличие зарубашечного пространства, используемого для охлаждающих их сред. Дополнительными линиями показаны пути охлаждающих компрессоры жидкостей - откуда они берутся и куда сбрасываются. Из совместного рассмотрения рис. 3 и рис. 4, с учётом подрисуночных подписей, можно уяснить принцип действия модифицированной холодильной установки, который отличается от принципа действия исходной установки. 


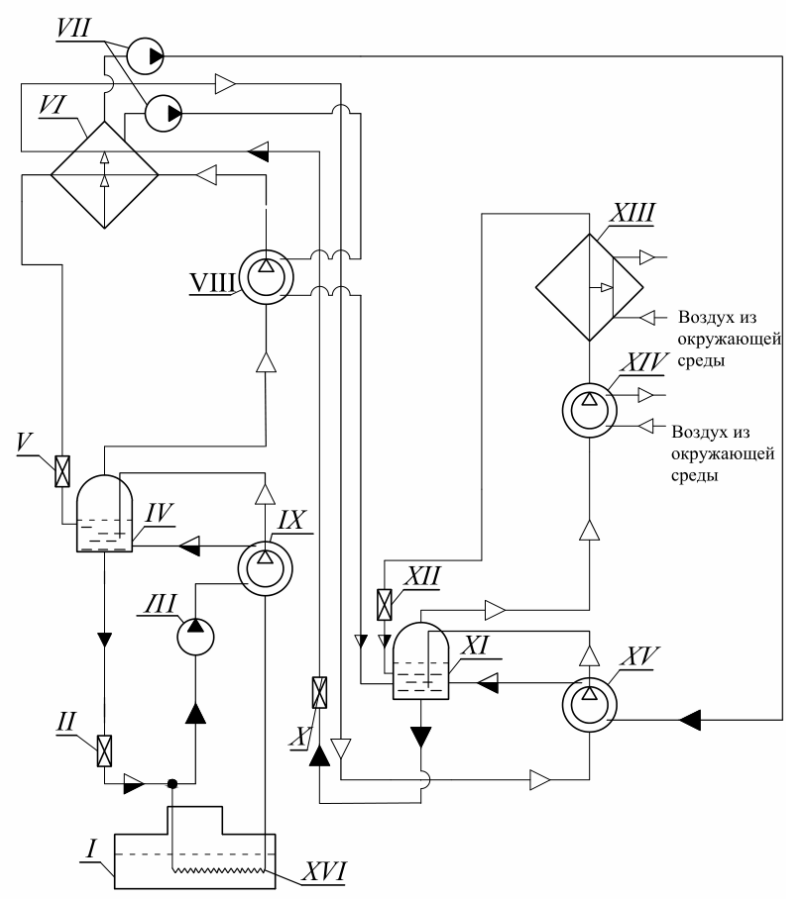

Рис. 4. Принципиальная схема двухкаскадной холодильной установки с политропными прочессами сжатия рабочих тел:

$\boldsymbol{I}$ - рефрижераторный контейнер; II - дроссельный вентиль, через который хладагент подаётся в испаритель контейнера;

III - ичиркуляиионные насосы, подающий жидкий этан в зарубашечное пространство КНД нижней ветви каскада; IV - промсосуд нижней ветви каскада; $\boldsymbol{V}$ - дроссель между второй и первой ступенью сжатия нижней ветви каскада; VI - конденсатор-испаритель

(этан конденсируется, пропилен кипит); VII- циркуляиионные насосы, подаюшие жидкий пропилен в зарубатечное пространство КВД нижней ветви каскада и КНД верхней ветви; VII - КВД нижней ветви каскада;

$\boldsymbol{I} \boldsymbol{X}-$ КНД нижней ветви каскада; $\boldsymbol{I} \boldsymbol{X}-$ КНД нижней ветви каскада; $\boldsymbol{X}$ - дроссельный вентиль, через который жидкий пропилен поступает

в конденсатор-испаритель; XI - промсосуд верхней ветви каскада; XII - дроссель между второй и первой ступенью сжатия верхней ветви каскада; $\boldsymbol{X I I I - \kappa о н д е н с а т о р ~ у с т а н о в к и ; ~} \mathbf{X I V}-$ КВД верхней ветви каскада; XV - КНД верхней ветви каскада; $\boldsymbol{X V I}$ - испаритель установки

Для подтверждения эффективности предлагаемого усовершенствования холодильной установки рефрижераторного контейнера выполнены тепловые расчёты сопоставляемых циклов при идентичных условиях их использования. Расчёты выполнялись по методике, изложенной в 
учебнике [9] с помощью автоматизированной информационной системы свойств рабочих тел энергетических и холодильных установок REFPROP [10]. Результаты сопоставительных расчётов приведены в табл. 1 и 2.

Таблииа 1

Сопоставление энергетических характеристик двухкаскадных холодильных ичиклов рефрижераторного контейнера при адиабатном и политропном проиессах сжатия

\begin{tabular}{|l|c|c|c|c|}
\hline \multirow{2}{*}{ Характеристики циклов } & \multicolumn{2}{|c|}{$\begin{array}{c}\text { Нижняя ветвь каскада } \\
\text { (этановая) }\end{array}$} & \multicolumn{2}{|c|}{$\begin{array}{c}\text { Верхняя ветвь каскада } \\
\text { (пропиленовая) }\end{array}$} \\
\cline { 2 - 5 } & \multicolumn{2}{|c|}{ сжатие } & \multicolumn{2}{|c|}{ сжатие } \\
\cline { 2 - 5 } & $\begin{array}{c}\text { адиабат- } \\
\text { ное }\end{array}$ & $\begin{array}{c}\text { поли- } \\
\text { тропное }\end{array}$ & $\begin{array}{c}\text { адиабат- } \\
\text { ное }\end{array}$ & $\begin{array}{c}\text { поли- } \\
\text { тропное }\end{array}$ \\
\hline $\begin{array}{l}\text { Тепловая нагрузка на кас- } \\
\text { кадную ветвь, кВт }\end{array}$ & \multicolumn{2}{|c|}{4,1} & 6,45 & 5,63 \\
\hline $\begin{array}{l}\text { Фактическая удельная мас- } \\
\text { совая холодопроизводи- } \\
\text { тельность, кДж/кг }\end{array}$ & 428,7 & 441,7 & 346,8 & 388 \\
\hline $\begin{array}{l}\text { Фактическая удельная } \\
\text { объёмная холодопроизводи- } \\
\text { тельность, кДж/м }\end{array}$ & 952,4 & 861,8 & 1796,2 & 727 \\
\hline Коэффициент подачи КНД & 0,5281 & 0,7138 & 0,6181 & 0,8335 \\
\hline $\begin{array}{l}\text { Теоретическая подача пара } \\
\text { КНД, м } / \text { с }\end{array}$ & 0,004305 & 0,004758 & 0,007067 & 0,006361 \\
\hline $\begin{array}{l}\text { Секундный объём, описы- } \\
\text { ваемый поршнями КНД, м }{ }^{3} / \mathrm{c}\end{array}$ & 0,006454 & 0,006665 & 0,01143 & 0,008937 \\
\hline $\begin{array}{l}\text { Теоретическая мощность } \\
\text { КНД, кВт }\end{array}$ & 0,5717 & 0,4515 & 1,278 & 1,025 \\
\hline $\begin{array}{l}\text { Индикаторная мощность } \\
\text { КНД, кВт }\end{array}$ & 1,083 & 0,6799 & 2,027 & 1,220 \\
\hline $\begin{array}{l}\text { Эффективная мощность } \\
\text { КНД, кВт }\end{array}$ & 1,416 & 1,013 & 2,599 & 1,667 \\
\hline Коэффициент подачи КВД & 0,5887 & 0,7302 & 0,6181 & 0,8335 \\
\hline $\begin{array}{l}\text { Теоретическая подача пара } \\
\text { КВД, м } / \text { с }\end{array}$ & 0,001914 & 0,001857 & 0,003160 & 0,001651 \\
\hline $\begin{array}{l}\text { Секундный объём, описы- } \\
\text { ваемый поршнями КВД, м }{ }^{3} / \mathrm{c}\end{array}$ & 0,002951 & 0,002544 & 0,005166 & 0,001981 \\
\hline $\begin{array}{l}\text { Теоретическая мощность } \\
\text { КВД, кВт }\end{array}$ & 0,7445 & 0,6256 & 2,312 & 1,085 \\
\hline $\begin{array}{l}\text { Индикаторная мощность } \\
\text { КВД, кВт }\end{array}$ & 1,265 & 0,8235 & 3,212 & 1,095 \\
\hline $\begin{array}{l}\text { Эффективная мощность } \\
\text { КВД, кВт }\end{array}$ & 1,413 & 1,013 & 3,470 & 1,194 \\
\hline
\end{tabular}


Анализируя данные, приведенные в таблице 1, можно утверждать:

- объём описываемый поршнями КНД нижней ветви каскада при переходе на политропный процесс сжатия увеличился на 3,3 \%, а КНД верхней ветви каскада уменьшился на $21,8 \%$;

- объём описываемый поршнями КВД нижней ветви каскада при переходе на политропный процесс сжатия уменьшился на 13,8 \%, а КВД верхней ветви - на 47,8 \%;

- эффективная мощность КНД нижней ветви каскада при переходе на политропный процесс сжатия уменьшилась на $28,5 \%$, а КНД верхней ветви каскада - на $35,9 \%$;

- эффективная мощность КВД нижней ветви каскада при переходе на политропный процесс сжатия уменьшилась на 28,3 \%, а КВД верхней ветви - на $65,6 \%$.

Таблийа 2

Сопоставление энергетических характеристик двухкаскадных холодильных установок рефрижераторного контейнера при адиабатном и политропном проиессах сжатия

\begin{tabular}{|l|c|c|}
\hline \multirow{2}{*}{ Характеристики циклов } & \multicolumn{2}{|c|}{$\begin{array}{c}\text { Значения характеристик холодильных } \\
\text { установок при сжатии }\end{array}$} \\
\cline { 2 - 3 } & адиабатном & политропном \\
\hline $\begin{array}{l}\text { Теоретическая мощность } \\
\text { установки, кВт }\end{array}$ & 4,91 & 3,19 \\
\hline $\begin{array}{l}\text { Индикаторная мощность } \\
\text { установки, кВт }\end{array}$ & 7,59 & 3,82 \\
\hline $\begin{array}{l}\text { Эффективная мощность } \\
\text { установки, кВт }\end{array}$ & 8,90 & 4,83 \\
\hline $\begin{array}{l}\text { Теоретический холодильный } \\
\text { коэффициент }\end{array}$ & 0,835 & 1,285 \\
\hline $\begin{array}{l}\text { Эффективный холодильный } \\
\text { коэффициент }\end{array}$ & 0,461 & 0,849 \\
\hline
\end{tabular}

Анализируя данные, приведенные в таблице 2, можна утверждать:

- при переходе на политропный процесс сжатия хладагентов во всех ветвях и ступенях двухкаскадной холодильной установки эффективная мощность установки уменьшилась на 4,07 кВт, или на 45,7 \%;

- эффективный холодильный коэффициент двухкаскадной холодильной установки при переходе на политропный процесс сжатия увеличился в 1,8 раза.

Выводы. Усовершенствовав термодинамический цикл двухкаскадной холодильной установки рефрижераторного контейнера для перевозки и хранения вакцины $N V X$-CoV2373 путём замены адиабатных про- 
цессов сжатия хладагентов политропными процессами, можно существенно уменьшить эффективную мощность холодильной установки. Суточная экономия электроэнергии на один контейнер составляет около 100 кВтч, а годовая - более 35 МВт॰час., что соответствует более 26 кг/сутки или около 10 т/год топлива при использовании для выработки электроэнергии дизель генератора с удельным расходом топлива 0,270 кг/кВт•час. Для 40 футовых контейнеров экономические показатели при соответствующих условиях их использования будут в 2 раза выше.

Улучшаются также массогабаритные и эксплуатационные показатели холодильной установки: можно устанавливать компрессоры меньшей производительности, и температура хладагентов в конце политропных процессов сжатия ниже. Последнее улучшает условия работы компрессоров и повышает их моторесурс.

Наконец, выполненное в статье исследование показывает перспективность использования политропного процесса сжатия в термодинамическом цикле холодильных установок рефрижераторных контейнеров. Распространив этот принцип работы холодильных установок на обычные рефрижераторные контейнеры, исчисляемые сейчас сотнями тысяч, можно экономить огромные средства, а главное уменьшить тепловое и газовое загрязнение атмосферы Земли, что является актуальной проблемой.

\section{ЛИТЕРАТУРА}

1. Вассерман А.А., Слинько О.Г. (2016). Спосіб здійснення теоретичного ичику парокомпресорних холодильних машин. Патент України №110869. Бюлетень «Промислова власність». № 4.

2. Вассерман А.А., Лавренченко Г.К., Слынько А.Г. (2014). Особенности идеализированных ичилов парокомпрессорных холодильных машин // Технические газы. - № 6.- С. 30-36.

3. Вассерман А.А., Слынько А.Г., Россомаха О.А. (2016). Повышение экономичности установок реконденсации пара сжиженных газов // Технические газы. - № 2. - С. 27-34.

4. Vasserman A.A., Slyn'ko A.G. Economy of Energy during Refrigerating Machines Operation (2016) // Journal of Mechanics Engineering and Automation. - V.6. - № 5. - P. 265-268.

5. Вассерман А.А., Сльнько А.Г. (2016). Повышение экономичности трёхкаскадной холодильной установки // Технические газы. - № 6. - C.61-63.

6. Вассерман А.А., Слынько А.Г. (2017). Уменьшение мощности привода компрессора для сжатия диоксида углерода при производстве карбамида // Технические газы. - № 2. - C.61-65. 
7. Вассерман А.А., Сльинько А.Г. (2017). Удосконалення циклу суднових парокомпресорних холодильних машин // Зб. наук. праць до 25-річчя ТАУ «Основні результати наукової діяльності Південного наукового центра», Одеса: ОНМУ. C. 25-27.

8. Вассерман А.А., Сльнько А.Г. (2017). Замена хладагента R22 озонобезопасным в трёхкаскадной установке реконденсации пара метана // Технические газы. - № 6. - С.62-67.

9. Загоруйко В.А., Голиков А.А. (2000). Судовая холодильная техника. - К.: Наукова думка. -607 c.

10. Lemmon E.W., Huber M.L. and McLinden M.O. (2007). NIST Reference Fluid Thermodynamic and Transport Properties REFPROP, Version 8.0. Gaithersburg, 51 p.

\section{REFERENCES}

1. Vasserman, A.A., Slyn ko A.G. (2016). Sposib zdiysnennya teoretychnogo tsyklu parokompresornykh kholodylnykh mashin (Method of realization of theoretical cycle of vapor compressor refrigerating machines). - Ukrainian patent on invention № 110869. Bulletin "Promyslova vlasnist » (Industrial property), 2016. - № 4.

2. Vasserman, A.A., Lavrenchenko G.K., Slyn ko A.G. (2014). Osobenosti idealizirovanuch ziklov parokompresornuch xolodul'nux machin // Technicheski gazu. - 2014. - № 6. - P. 30-36.

3. Vasserman, A.A., Slyn'ko, A.G., Rossomasha, O.A. (2016). Povushenie ekonomichnosti ystanovok rekondensachii para schuchenuch gasiv // Technicheskie gazu. - № 2. - P. 30.-36.

4. Vasserman, A.A., Slyn'ko, A.G. Economy of Energy during Refrigerating Machines Operation (2016) // Journal of Mechanics Engineering and Automation. - V.6. - № 5. - P. 265-268.

5. Vasserman, A.A., Slyn'ko, A.G. Povuchenie ekonomichnosti trochkaskadnoi xolodil'noi ystanovku (2016). Technicheskie gazu. № 6. - C.61-63.

6. Vasserman, A.A., Slyn'ko, A.G. (2017). Ymenshenie mochnosti privoda kompresora dlie znietiea dioksida ygleroda pri proizvodstve karbamida // Technicheskie gazu. - № 2. - P. 30-36.

7. Vasserman, A.A., Slyn'ko, A.G. (2017) Ydoskonalenia chikly sydnovuch parokompesornuch cholodulnuch mashin // Zb. Nayk. prach do 25-richia TAY«Osnovni rezultatu naykovoi diyalnosti pivdennogo naykovogo chenry». - Odessa: ONMY. -P. 25-27.

8. Vasserman, A.A., Slyn'ko, A.G. (2017) / Zamena chladagenty R22 ozonobezopasnum $v$ triechkaskadnoi ystanovke recondensachii para metana // Technicheskie gazu. - № 2. - P.61-65. 
ВІСНИК

ОДЕСЬКОГО НАЦІОНАЛЬНОГО

МОРСЬКОГО УНІВЕРСИТЕТУ

№ 1 (64), 2021
HERALD

OF THE ODESSA NATIONAL

MARITIME UNIVERSITY № 1 (64), 2021

9. Zagoruyko, V.A., Golikov, A.A. (2000). Sudovye kholodylnye ustanovki (Ships' refrigerating plants). - K.: Publ. house "Naukova dumka (Scientific thought)». - 607 p. (Rus).

10. Lemmon, E.W., Huber, M.L., McLinden, M.O. (2007). NIST Reference Fluid Thermodynamic and Transport Properties REFPROP, Version 8.0. Gaithersburg, 51 p.

Стаття надійшла до редакиії 28.12.2020

Посилання на статтю: Вассерман А.А., Слынько. Усовершенствование термодинамического цикла холодильной установки рефрижераторного контейнера для перевозки и хранения вакцины NVX-CoV2373 // Вісник Одеського національного морського університету: Зб. наук. праць, 2021. № 1 (64). С. 60-71. DOI 10.47049/ 2226-1893-2021-1-60-71.

Article received 28.12.2020

Reference a JournalArtic: Vasserman A.A., Slyn`ko A.G. Improvement of thermodynamic cycle refrigerating installation container for transportation and storage of vaccine NVX-Cov2373 // Herald of the Odessa national maritime university. 2021. 1(64), 60-71. DOI 10.47049/2226-1893-2021-1-60-71. 